\title{
Case Report about a Primary Bladder Lymphoma
}

\author{
Nina Combaz ${ }^{1 *}$ and Annette Kuhn ${ }^{2}$ \\ ${ }^{1}$ Obstetrics and Gynaecology, Kantonsspital Sitten, Avenue du Grand-Champsec, Switzerland \\ ${ }^{2}$ Urogynäkologie Frauenklinik Inselspital Bern, Effingerstrasse, Switzerland
}

*Corresponding author: Dr. Nina Combaz, Obstetrics and Gynaecology, Kantonsspital Sitten, Avenue du Grand-Champsec 80, 1951 Sion, Switzerland, Tel: +41-27-480-44-60, Fax: +41-27-566-71-66, E-mail: Dr.Combaz@cabinet-gynecologie.ch

\begin{abstract}
Primary isolated bladder lymphoma represents around $0.2 \%$ of all extranodal Non-Hodgkin-Lymphoma and less than $1 \%$ of all bladder tumours. Clinical representation may be unspecific and correct diagnosis is essential for the appropriate treatment. We expose the case of a patient with a primary B-cell bladder lymphoma with normal cystoscopy.

Case report: A 67-year-old patient presented with lower urinary tract infections, overactive bladder with urinary incontinence as well as haematuria susceptible for bladder carcinoma. Urine sediment, cytologie, abdominal- and kidney ultrasound as well as a CT scan did not lead to a conclusive diagnosis. Surprisingly, cystoscopy did not demonstrate any tumourous lesions and urine cytology revealed free of malignant cells. Cold four-quadrant cut biopsies finally did reveal the presence of a primary B-cell lymphoma. After a four weeks' antibody treatment of Rituximab (Mabthera) the patient showed subjective improvement and lower urinary tract symptoms disappeared. Clinical follow-up as well as repeat cystoscopic biopsies were undertaken every six months. After a follow-up period of nearly three years the patient is still in complete remission. Urinary tract infections and incontinence as well as OAB symptoms disappeared entirely.

Discussion: Haematuria was the main clinical finding in the current case of primary bladder lymphoma. Uneventful radiologic examinations lead to the necessity of bladder biopsies without any macroscopic pathologic findings. We present the exceedingly rare case of a primary bladder lymphoma without any characteristic lesions in the bladder lumen. For this reason, cystoscopic four quadrant biopsies should be used largely. Biopsies are essential leading to the correct diagnosis and finally successful treatment. Single antibody therapy with Rituximab is an option in selected cases as the one presented and can be used as un therapeutic option.
\end{abstract}

\section{Keywords}

Bladder lymphoma, Cystoscopy, Overactive bladder, Urinary tract infections, Rituximab

\begin{abstract}
Abbreviations
BMI: Body Mass Index; CHOP: Cyclophosphamide Doxorubicin Vincristine Prednisone; CT-Scan: Computerized Tomography Scan; DLBCL: Diffuse Low B-Cell Lymphomas; FISH: Fluorescence In Situ Hybridization; GI Tract: Gastrointestinal Tract; MALT: Mucosa Associated Lymphoid Tissue; NHL: Non-Hodgkin's Lymphomal; Pet-Scan: Positron Emission Tomography Scan; R-CHOP: Rituximab Cyclophosphamide Daunorubicin Vincristine Prednisolone; TURBT: Transurethral Resection of Bladder Tumour
\end{abstract}

\section{Introduction}

Primary lymphoma of the bladder is rare. It constitutes $5 \%$ of the nonurothelial tumour of the urinary tract [1] Primary isolated bladder lymphoma represents only $0.2 \%$ of all extranodal Non-Hodgkin-Lymphoma and less than $1 \%$ of all bladder tumours [2,3]. Of primary lymphomas of the bladder, mucosa associated lymphoid tissue lymphoma, or MALT, is the most prevalent histological subtype. Till today little more than 100 cases have been reported. The clinical, radiological and endoscopic representation may be unspecific which conducts to the fact that diagnostic features may not be well known by the unaccustomed practitioner. The diagnosis is exclusively histological. Furthermore, the optimal treatment of primary MALT confined to the bladder remains to be defined.

We expose the rare case of a primary B-cell bladder lymphoma (Malt-type), treated with Rituximab and a review of the appropriate literature.

We want to share this rare case with its unspecific clinical symptoms in order to alert our colleagues to the important role of biopsy in prompt diagnosis. We em-

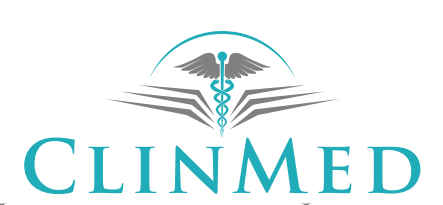

INTERNATIONAL LIBRARY
Citation: Combaz N, Kuhn A (2017) Case Report about a Primary Bladder Lymphoma. Int Arch Urol Complic 3:030. doi.org/10.23937/2469-5742/1510030

Received: June 16, 2017: Accepted: September 28, 2017: Published: September 30, 2017

Copyright: (C) 2017 Combaz N, et al. This is an open-access article distributed under the terms of the Creative Commons Attribution License, which permits unrestricted use, distribution, and reproduction in any medium, provided the original author and source are credited. 
phasize on the high index of suspicion required to identify such cases at an early stage, which has pronounced prognostic implications.

\section{Case Report}

A 67-years-old female presented with a history of a couple of months lasting asthenia, inappetence weight loss of $5 \mathrm{~kg}$ in one-year, recurrent lower urinary tract infections which were commonly treated by antibiotics, lower abdominal pain, overactive bladder with urinary incontinence and a two-week lasting macroscopic haemorrhagic cystitis which did not disappear after eradication of an Escherichia coli infection. No other underlying medical conditions were known. On examination, the woman was sallow, abdominal palpation was physiologic, neither organomegaly nor lymphadenopathy could be found.

Urine culture showed sterile pyuria. Urine sediment, urine cytology, a complete blood count, biochemical analyse of renal function and abdominal- and kidney ultrasound as well as a computertomographie didn't give any hint of the underlying pathology. Rigid cystoscopy showed signs of chronic infections and bleeding bladder walls (Figure 1). Only cystoscopic four quadrant biopsies could reveal the diagnosis: Histopathology features were those of a non-Hodgkin's lymphoma, compatible with an extranodal low malignant marginal zone B-cell lymphoma of mucosa-associated lymphoid tissue (MALT lymphoma, WHO classification of 2008) [1] based on chronic cystitis. Cells were positive for CD20. Laboratory evaluation including protein electrophoresis was all within normal limits.

Subsequently, a PET-CT scan of the abdomen and pelvis was performed, which revealed diffusely thickened bladder walls with a moderate uptake of the bladder (Figure 2). There was no sign of paravesical fat

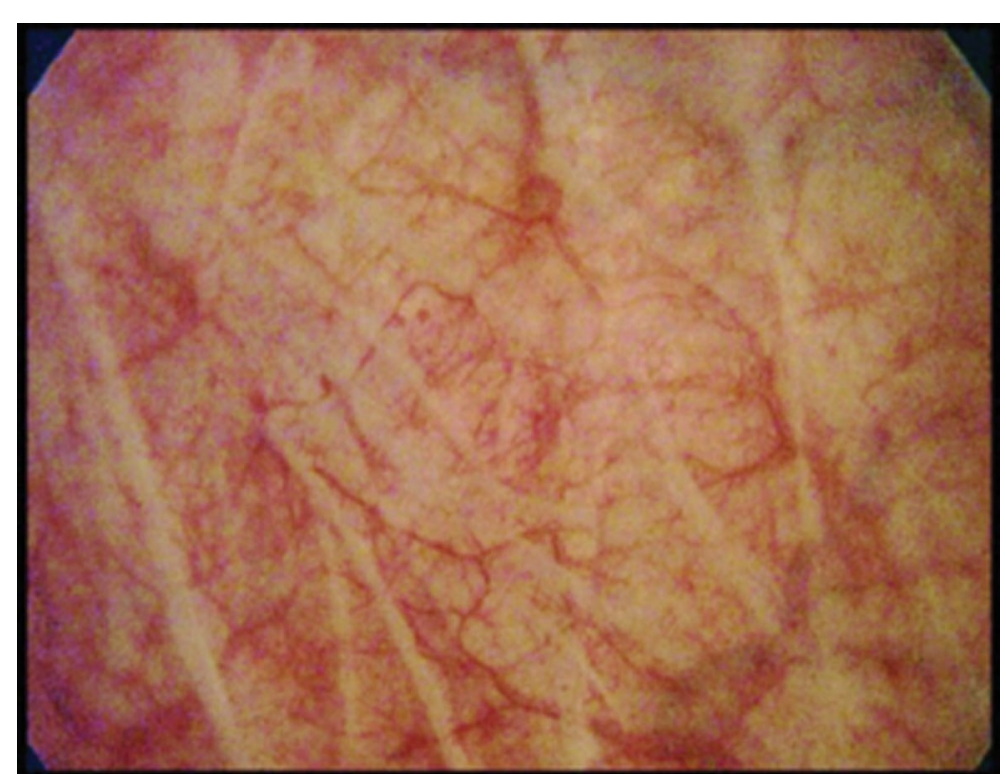

Figure 1: Initial Cystoscopy with signs of chronic infection and bleeding bladder walls but without any tumourous lesion.

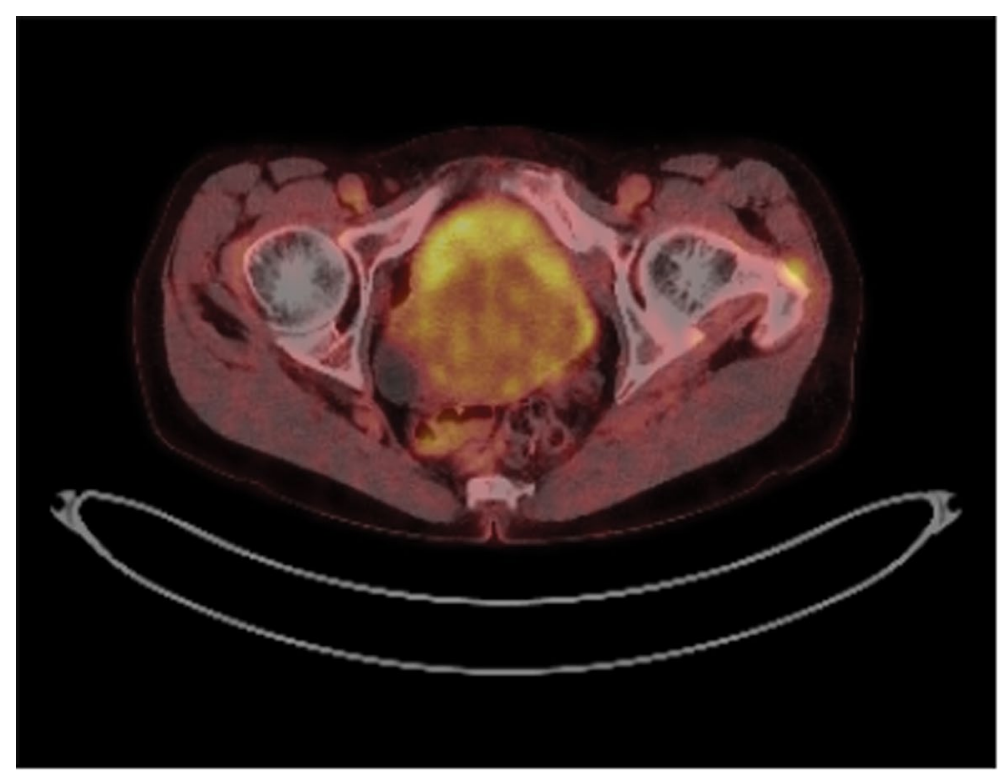

Figure 2: Pet-Scan revealed diffuse thickened, metabolic active bladder walls. 
infiltration and no pelvic or abdominal lymph node enlargement or any other anomaly. Due to the highly invasive nature of the tumour, bone marrow biopsy was performed. It showed no evidence of leukaemia or lymphoma.

After a 4-week lasting antibody treatment once a week with Rituximab (Mabthera) $375 \mathrm{mg} / \mathrm{m}^{2}$ patient felt better and lower abdominal pain disappeared. Clinical controls combined with Cystoscopic biopsies and pelvic CT-scans were undertaken every 6 months for two years and later on once a year.

After a follow-up period of nearly three years our patient is still in complete remission. Haematuria, urinary tract infections and overactive bladder associated incontinence disappeared totally.

\section{Discussion}

Primary lymphoma of the bladder is an exceeding rare malignancy. Its rarity and symptoms common for chronic cystitis often delay its diagnosis. Data to guide therapy is limited.

Bladder lymphoma was first described in 1985 by Eve and Chaffey [2]. Just over 100 cases have been reported since. Extranodal marginal zone lymphoma of mucosa associated lymphoid tissue type (MALT-type lymphoma) of the urinary bladder, first described in 1990 , is the most common primary bladder lymphoma $[2,4,5]$. On histology most, cases are low-grade lymphomas [6]. B-cell bladder lymphomas are more frequently seen than T-cell ones [5]. Kempton, et al. found out that only 6 of all documented bladder lymphomas registered between 1940 to 1996 in the Mayo tissue registry are primary [4].

The rare occurrence of this neoplasm is a consequence of the fact that there are no germinal follicles or lymphoid tissue developing in the urinary bladder itself [7]. Hereby, the aetiology of such malignancies remains unknown. The MALT concept provides a mechanism by which malignant lymphomas could develop in the bladder and in other sites of the body that normally possess no lymphoid tissue, after long-standing antigenic stimulation by bacterial infection [8-10]. As such, patients often present, like the here exposed case, with symptoms of chronic cystitis [5,11-13]. This theory is supported by the fact that lymphoepithelial lesions are seen in MALT lymphoma [9-14]. However, cases in which chronic cystitis and histological inflammation are lacking have been cited $[7,11,14]$. The base for disease development in these cases is still unknown. Other authors have raised the possibility of a residual embryonic cloaca, from which the bladder derives, source lymphoid proliferation in adulthood [15].

Female preponderance for illness is preeminent $[6,7,11-13]$, which is contrary to the male predominance of primary urinary bladder carcinoma [16]. MALT-lym- phoma of the bladder may be more frequent in female potentially as a result of increased incidence of chronic cystitis in women. The disease typically presents in the 6 th decade of life with a mean age at presentation of 64 years $[4-6,12]$.

Our patient presented the typical most common symptoms of lymphoma of the urinary bladder: Macroscopic haematuria (present in 61\% [5]) and signs of bladder irritation (dysuria, nycturia, urinary frequency, and suprapubic or abdominal pain $[4,6,11,13])$ combined with weight loss, fatigue and recurrent urinary tract infections.

Bladder lymphoma presents at imaging in $70 \%$ as a solitary submucosal mass and, less commonly, as multiple masses $(20 \%)$ or diffuse bladder wall thickening (10\%) [17]. The location is most often centred in the dome or lateral walls of the urinary bladder [17]. It usually involves the submucosa without mucosal ulceration [18]. The radiologic findings are nonspecific and do not permit to differentiate from other bladder neoplasms by imaging alone [19]. Diagnosis relies on cystoscopic biopsies, and a thorough pathologic evaluation of biopsied tissue [20].

MALT lymphomas of the bladder, in common with those at other sites, generally carry a good prognosis and have little tendency to disseminate to non-MALT lymphoid organs. Nevertheless, dissemination or to transform into higher grade DLBCL [21] is possible, implying that an early diagnosis of the MALT lymphoma is important for improved prognosis [22].

On cystoscopy, these tumours are visualized as well-defined intravesicular masses typically located at the dome, retro-trigonal or the lateral walls of the blad$\operatorname{der}[20,23]$. An oedematous, haemorrhagic or friable mucosa may be associated [13]. Ulcerous lesions may be present [20].

Pathological analysis should include immunohistochemical staining, FISH testing, and microscopic evaluation of the tumor grade $[7,24]$. The B-cell lymphoma is characterized by a proliferation of atypical monomorphic lymphoid cells. Differential diagnosis with poorly differentiated carcinoma; melanoma, Burkitt's and Hodgkin's lymphoma may be throw out using the immunohistochemical panel. FISH testing permits to detect the three main types of B-cell derived Non-Hodgkin's Lymphoma (NHL) with strongly associated FISH test abnormalities: Burkitt's lymphoma t (8:14) translocation of MYC gene, mantle cell lymphoma $t$ (11:14) translocation of cyclin D1 gene, and follicular lymphoma $t$ (14:18) translocation of BCL-2 gene. Absence of any of these translocations does not exclude diagnosis as they are not present in $100 \%$ of cases [25]. All B-cell type lymphomas are CD20 positive in immunhistochemical testing [17]. Low grade lymphomas routinely test positive for CD20, CD21, and CD43 cell markers, while high 
grade lymphomas are correlated with $\mathrm{CD} 3, \mathrm{CD} 20$, and CD30 cell markers [14]. Lymphomas of the urinary bladder stain negatively with Pan-keratin, vimentin, CK20, and CK7 [17].

Once the type of bladder lymphoma has been identified, differentiation between an indolent, low grade neoplasm versus an aggressive, high grade malignancy is important in order to initiate the most appropriate treatment regimen for that patient. The average age at diagnosis of high grade lymphoma is 10 years younger than that of low grade ones [7]. Aggressive high-grade lymphoma without treatment leaves the patient with a prognosis of a matter of months [26].

Staging becomes of utmost importance. It should eliminate the presence of any other lesions to confirm the primary origin of the bladder lymphoma. It must include hole body PET-scan and bone marrow biopsy $[2,27]$.

Common used treatment options for non gastric MALT lymphomas are:

I. Observation (based on factors such as patient age, risk factors, other underlying medical problems and tumour grade) [9].

II. Surgery (complete excision or biopsy) [28].

III. Radiation (radiation, when given alone or after an excisional biopsy, has shown excellent local control and improved overall disease-free survival) $[17,29]$.

IV. Chemotherapy (usually used when a patient presents with systemic involvement or secondary lymphoma of the bladder) $[10,30]$.

V. Targeted antibody therapy (by the anti-CD20 antibody rituximab) has been used along with other modalities in systemic lymphomas $[10,30,31]$.

VI. Antibiotics (they are usually used in presence of a known bacterial origin for chronic infections, e.g. Helicobacter pylori in the stomach). There have been rare cases where antibiotics were used for MALT lymphomas of the bladder [5,32]. Probably the prosperity of this treatment can be explained with the lymphoma development on an underlying chronic cystitis.

No treatment recommendations based on lesion size have been published. For this reason, Simpson, et al. [7] proposed recently to use the following criteria set for other bladder tumours:

- TURBT has proven effective in urothelial bladder cancer that has yet to invade the musclaris propria (stage Ta, Tis, and T1).

$>$ Radiation alone proved to be successful in only $66 \%$ (2 of 3 ) cases.

$>$ As for the type of chemotherapy different regimens were successfully used treating low grade bladder lymphomas [7]; $\mathrm{CHOP}$ was reported by the literature to be the most frequently applied $[5,15,20,28]$. It has documented success in treating both low and high grade primary bladder lymphomas as either solitary treatment or combination therapy [15]. The addition of rituximab in cases of $C D 20$ positivity should be systematic due to the therapeutic benefit provided by this monoclonal antibody in this situation $[10,28,33]$.

As low-grade lymphomas are highly radiosensitive and the disease-free outcome is very good [6] Vempati, et al. concluded that radiotherapy is the most appropriate treatment for localized disease [34] in order to achieve organ preservation. For patients at reproductive age, the authors postulated to use maximal surgical resection with the aim to preserve fertility as radiation of the bladder may be harmful to the proximal reproductive organs [34].

Chemotherapy and rituximab are often used for secondary, recurrent, or disseminated disease [10]. In summary the treatment is not well defined [35] and the prognosis remains unknown $[20,28]$.

The current patient presented local infiltration of the bladder. Surgical excision would have meant bladder excision and did not present an option. Local radiation would have been a possibility. Rituximab targets the $C D$ 20 cell surface protein, present on B-cells and on most B-cell malignancies. Its various effects are: Cell lysis, antibody dependant cellular cytotoxicity and induction of apoptosis $[33,36]$. As a single agent therapy Rituximab has been shown effective in DLBCL treatment [37]. Finally, based on own experiences with antibody monotherapy in primary lymphoma of other organs, our oncological tumour board proposed a monotherapy with Rituximab.

This is at our knowledge the first published report of a monotherapy with Rituximab as first line single-agent therapy of a primary low-grade MALT lymphoma of the bladder.

The optimal follow-up strategy for patients with lymphoma of the bladder remains unknown [34]. Our patient was followed clinically, combined with urine cytology, rigid cystoscopy and four quadrant biopsies and pelvic scans every six months for two years and later on once a year, as it is recommended for transitional cell carcinoma. Nearly 3 years after the initial diagnosis she is still in complete remission. The prognosis is difficult to be determined given the rarity of primary $\mathrm{NHL}$ of the bladder. In concordance to the literature we hope and expect long term survival without remission $[4,5,7,13,14]$.

In conclusion, primary low-grade MALT lymphoma of the bladder represents a rare malignancy with excellent prognosis if detected at an early stage $[5,7,13,14,38]$. For this reason, practitioners should know about this entity and its presentation. Four quadrant cystoscopic 
biopsy must be used without hesitation after exclusion of other underlying causes. Early diagnosis implies excellent prognosis and increased patient survival. For early stage disease, antibody treatment alone with Rituximab presents nearly no side-effect profile $[10,34,37,39]$ and may be considered as an option for local disease treatment as an alternative to radiotherapy or excision. A second line chemotherapy or radiotherapy may be indicated in cases of locoregional recurrence. Treatment standardisation is difficult because of the few cases worldwide. Other reports of experiences with this treatment are crucial.

\section{Acknowledgement}

We thank Dr. Etienne Combaz for his support and technical assistance.

\section{Competing Interests}

The authors declare that they have no competing of interest.

\section{Authors' Contributions}

All authors have made significant contributions by making diagnosis, treatment and intellectual input in this study and writing the manuscript. All authors read and approved the final manuscript.

\section{References}

1. Marx A (2004) World Health Organization Classification of Tumors: Pathology and Genetics of Tumors of the Urinary System and Male Genital Organs. In: Eble JN, Sauter G, Epstein IJ, Sesterhen IA, IARC Press, Lyon, 147.

2. Maninderpal KG, Amir FH, Azad HA, Mun KS (2011) Imaging findings of a primary bladder maltoma. $\mathrm{Br} \mathrm{J}$ Radiol 84: e186-e190.

3. Rohena-Quinquilla IR, Lattin GE Jr, Wolfman D (2016) Imaging of extranodal genitourinary lymphoma. Radiol Clin North Am 54: 747-764.

4. Kempton CL, Kurtin PJ, Inwards DJ, Wollan P, Bostwick DG (1997) Malignant lymphoma of the bladder: evidence from 36 cases that low-grade lymphoma of the MALT-type is the most common primary bladder lymphoma. Am J Surg Pathol 21: 1324-1333.

5. Hughes M, Morrison A, Jackson R (2005) Primary bladder lymphoma: Management and outcome of 12 patients with a review of the literature. Leuk Lymphoma 46: 873-877.

6. Venyo AK (2014) Lymphoma of the urinary bladder. Adv Urol 2014: 327917

7. Simpson WG, Lopez A, Babbar P, Payne LF (2015) Primary bladder lymphoma, diffuse large B-cell type: Case report and literature review of 26 cases. Urol Ann 7: 268-272.

8. Isaacson PG, Norton AJ (1994) Malignant lymphoma of the gastrointestinal tract. In: Isaacson PG, Norton AJ, Extranodal Lymphomas. Edinburgh, 15-65.

9. Pawade $\mathrm{J}$, Banerjee SS, Harris $\mathrm{M}$, Isaacson $\mathrm{P}$, Wright $\mathrm{D}$ (1993) Lymphomas of mucosa-associated lymphoid tissue arising in the urinary bladder. Histopathology 23: 147-151.

10. Raderer M, Wohrer S, Streubel B, Drach J, Jager U, et al. (2006) Activity of rituximab plus cyclophosphamide, doxo- rubicin/mitoxantrone, vincristine and prednisone in patients with relapsed MALT Iymphoma. Oncology 70: 411-417.

11. Ohsawa M, Aozasa K, Horiuchi K, Kanamaru A (1993) Malignant lymphoma of bladder. Report of three cases and review of the literature. Cancer 72: 1969-1974.

12. Al-Maghrabi J, Kamel-Reid S, Jewett M, Gospodarowicz M, Wells W, et al. (2001) Primary low-grade B-cell lymphoma of mucosa-associated lymphoid tissue type arising in the urinary bladder: Report of 4 cases with molecular genetic analysis. Arch Pathol Lab Med 125: 332-336.

13. Guthman DA, Malek RS, Chapman WR, Farrow GM (1990) Primary malignant lymphoma of the bladder. J Urol 144: 1367-1369.

14. Bates AW, Norton AJ, Baithun SI (2000) Malignant lymphoma of the urinary bladder: A clinicopathological study of 11 cases. J Clin Pathol 53: 458-461.

15. Horasanli K, Kadihasanoglu M, Aksakal OT, Ozagari A, Miroglu C (2008) A case of primary lymphoma of the bladder managed with multimodal therapy. Nat Clin Pract Urol 5: 167-170.

16. Wong-You-Cheong JJ, Woodward PJ, Manning MA, Sesterhenn IA (2006) From the Archives of the AFIP: neoplasms of the urinary bladder: radiologic-pathologic correlation. Radiographics 26: 553-580.

17. Levy G (2016) Bladder other tumors lymphoma (primary).

18. Charnsangavej C (1990) Lymphoma of the genitourinary tract. Radiol Clin North Am 28: 865-877.

19. Raman SP, Fishman EK (2014) Bladder malignancies on CT: The underrated role of CT in diagnosis. AJR Am J Roentgenol 203: 347-354.

20. Peyromaure M, Van Glabeke E, Leblond V, Barrou B, Delcourt A, et al. (2000) Primary lymphoma of the bladder. Prog Urol 10: 1208-1211.

21. Wazait HD, Chahal R, Sundurum SK, Rajkumar GN, Wright D, et al. (2001) MALT-type primary lymphoma of the urinary bladder: clinicopathological study of 2 cases and review of the literature. Urol Int 66: 220-224.

22. Cogliatti SB, Schmid U, Schumacher U, Eckert F, Hansmann ML, et al. (1991) Primary B-cell gastric lymphoma: A clinicopathological study of 145 patients. Gastroenterology 101: 1159-1170.

23. Khaitan A, Gupta NP, Goel A, Safaya R, Kumar L (2004) Primary non-Hodgkin's lymphoma of urinary bladder. Report of a case and review of the literature. Urol Int 72: 82-84.

24. Zukerberg LR, Harris NL, Young RH (1991) Carcinomas of the urinary bladder simulating malignant lymphoma: $A$ report of five cases. Am J Surg Pathol 15: 569-576.

25. Ventura RA, Martin-Subero JI, Jones M, McParland J, Gesk S, et al. (2006) FISH analysis for the detection of lymphoma-associated chromosomal abnormalities in routine paraffin-embedded tissue. J Mol Diagn 8: 141-151.

26. Freedman A, Friedberg $J(2017)$ Initial treatment of advanced stage diffuse large B cell lymphoma. UpToDate.

27. Mahfoud T, Tanz R, Mesmoudi M, Khmamouche MR, EI Khannoussi B, et al. (2013) Primary non-Hodgkin's lymphoma of the bladder: Case report and literature review. Pan Afr Med J 15: 136.

28. Ando K, Matsuno Y, Kanai Y, Sakamoto M, Fujimoto H, et al. (1999) Primary low-grade lymphoma of mucosa-associated lymphoid tissue of the urinary bladder: A case report with special reference to the use of ancillary diagnostic studies. Jpn J Clin Oncol 29: 636-639. 
29. Hatano K, Sato M, Tsujimoto $Y$, Takada T, Honda M, et al (2007) Primary mucosa-associated lymphoid tissue (MALT) lymphoma of the urinary bladder associated with left renal pelvic carcinoma: A case report. Hinyokika Kiyo 53: 57-60.

30. Kakuta Y, Katoh T, Saitoh J, Yazawa K, Hosomi M, et al (2006) A case of primary mucosa-associated lymphoid tissue lymphoma of the bladder regressed after rituximab in combination with $\mathrm{CHOP}$ chemotherapy. Hinyokika Kiyo 52 : 951-954.

31. Terasaki $Y$, Okumura $H$, Ishiura $Y$, Yokawa $S$, Kuribayashi $M$, et al. (2008) Primary mucosa-associated lymphoid tissue lymphoma of the urinary bladder successfully treated by radiotherapy and rituximab. Rinsho Ketsueki 49: 30-34.

32. Lucioni M, Nicola M, Riboni R, Croci GA, Rattotti S, et al. (2013) Antibiotic therapy-induced remission of bladder mucosa-associated lymphoid tissue (MALT) lymphoma carrying $\mathrm{t}(11 ; 18)(\mathrm{q} 21 ; \mathrm{q} 21)$ apoptosis inhibitor 2-MALT1. J Clin Oncol 31: e304-e306.

33. Anderson DR, Grillo-López A, Varns C, Chambers KS, Hanna N (1997) Targeted anti-cancer therapy using rituximab, a chimaeric anti-CD20 antibody (IDEC-C2B8) in the treatment of non-Hodgkin's B-cell lymphoma. Biochem Soc Trans 25: 705-708.
34. Vempati $P$, Knoll MA, Alqatari M, Strauchen J, Malone AK, et al. (2015) MALT Lymphoma of the Bladder: A Case Report and Review of the Literature. Case Rep Hematol 2015: 934374

35. Bacalja J, Ulamec M, Rako D, Bošković L, Trnski D, et al. (2013) Persistence of primary MALT lymphoma of the urinary bladder after rituximab with CHOP chemotherapy and radiotherapy. In Vivo 27: 545-549.

36. Reff ME, Carner K, Chambers KS, Chinn PC, Leonard JE, et al. (1994) Depletion of B cells in vivo by a chimeric mouse human monoclonal antibody to CD20. Blood 83: 435-445.

37. Coiffier B, Haioun C, Ketterer N, Engert A, Tilly $H$, et al. (1998) Rituximab (anti-CD20 monoclonal antibody) for the treatment of patients with relapsing or refractory aggressive lymphoma: a multicenter phase II study. Blood 92: 19271932.

38. Leite KR, Bruschini H, Camara-Lopes LH (2004) Primary lymphoma of the bladder. Int Braz J Urol 30: 37-39.

39. Sehn LH, Donaldson J, Chhanabhai M, Fitzgerald C, Gill $\mathrm{K}$, et al. (2005) Introduction of combined CHOP plus rituximab therapy dramatically improved outcome of diffuse large B-cell lymphoma in British Columbia. J Clin Oncol 23: 5027-5033 